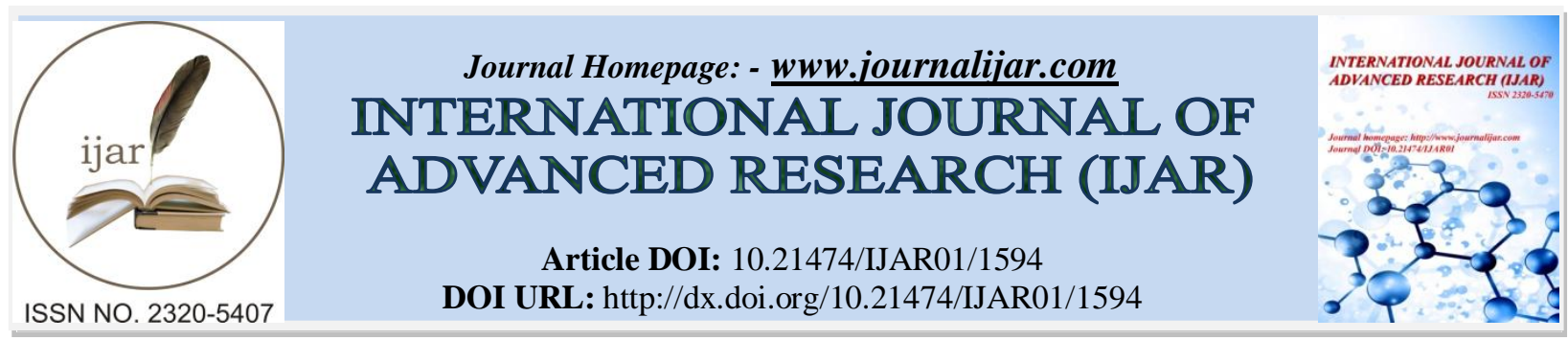

RESEARCH ARTICLE

\title{
ASTHMA QUALITY OF LIFE QUESTIONNAIRE (AQLQ-MEDAN) AS ALTERNATIVE ASSESSMENT FOR THE QUALITY OF LIFE IN PATIENTS WITH ASTHMA IN MEDAN CITY, INDONESIA.
}

\author{
Arlinda Sari Wahyuni ${ }^{1}$, Rozaimah Zain-Hamid ${ }^{2}$, Tamsil Syafiuddin ${ }^{3}$ and Adang Bachtiar ${ }^{4}$. \\ 1. Department of Community Medicine Medical School of USU. \\ 2. Department of Pharmacology and Therapeutic Medical School of USU. \\ 3. Department of Pulmonary and Respiratory Medicine Medical School of USU. \\ 4. Department of Health Administration and Policy Public Health School of Universitas Indonesia.
}

\section{Manuscript Info}

Manuscript History

Received: 26 July 2016

Final Accepted: 16 August 2016

Published: September 2016

Key words:-

AQLQ-Medan, asthma, patients, Medan, Indonesia.

\section{Abstract}

Asthma Quality of Life Questionnaire (AQLQ) which was developed to measure the functional disorders in patients with asthma $>17$ years old, consists of 32 items divided into four domains (symptoms, activities, emotional limitations, and environmental stimuli). The objective of this research is to determine the instrument used to measure the quality of life in patients with asthma that is valid, reliable, practical, cost-effective, and applicable in Medan city Indonesia. The method applied in this research was qualitative and quantitative approach method. Qualitative study was applied to develop a research instrument by using informations from the patients, specialists, general practitioners, and pharmacologists. Quantitative study was applied by cross-sectional approach. The sample was 200 adults patients with asthma who were using standard asthma medicine, as the combination of inhaled corticosteroid and LABA, the patients were stable and were not suffering from severe asthma or other comorbid diseases, such as heart diseases, hypertension, diabetes mellitus, liver and renal diseases. The sampling method used was consecutive sampling using data collected from general practitioners and pulmonologists. The research was conducted for 14 months (2011-2012). The validity and reliability of the quality of life questionnaire were determined by Pearson's correlation analysis, Alpha Cronbach, and confirmatory analysis. The results of this research indicated that the number of valid and reliable questions were 16 items that consisted of 3 health aspects, 4 emotional aspects, 5 environment aspects, and 4 limitation of activity aspects. The value of Alpha Cronbach for all the items was 0.929 and value of loading factor for health, emotional, environmental, and limitation of activity aspects were $0.72,0.78,0.64$, and 0.87 , respectively. The results of model fit indicated by the Goodness of fit with Chi square test 0.509, p 0.775, CMIN/DF 0.266, GFI 0.999, AGFI 0.994, TLI 1.014, CFI 1.000, and RMSEA 0.0001. The results of significant test of the weight factor were 0.0001 which indicated that all of the indicators can be used as the instrument to measure the quality of life in patients with asthma. 
Copy Right, IJAR, 2016,. All rights reserved.

\section{Introduction:-}

Quality of life is the level of individual's capability, limitation, symptoms, and psychosocial characteristics to function in any desired role in society and be satisfied on the role. The quality of life related to health describes the level of health in individual with a certain disease and the treatment received based on the standard treatment procedure for the disease. The quality of life can be used as a measurement of many aspects that depict an individual's perspective to prosperity and appearance, such as physical capability, occupation, psychology, social interaction, hobby, and recreation ${ }^{1}$.

The quality of life in patients with asthma is an important measurement as it is relevant with the dyspnea that disturbs with daily activities in patients with asthma or they who were functionally impaired in self-caring, mobility, food consumption, dressing, and household activites. The quality of life in patients with asthma can be assessed by using the health questionnaire Short Form-36 (SF36) and Asthma Quality of Life Questionnaire (AQLQ) ${ }^{2}$.

The development of instruments for assessing the quality of life in patients with asthma had been conducted by many researchers. One of those instruments is Asthma Quality of Life Questionnaire (AQLQ) which was developed to measure the functional disorders in patients with asthma $>17$ years old. This questionnaire consists of 32 items divided into four domains (symptoms, activities, emotional limitations, and environmental stimuli) ${ }^{3}$. But, in Indonesia, this instrument has not been used widely and there has not been any research on its validity and reliability for measuring the quality of life in patients with asthma.

Generally, the measurement of the quality of life in patients with asthma in Indonesia is often defined by asthma in or not in control using Asthma Control Test (ACT). Despite of its high validity and reliability $(0.84)^{4}$, ACT only measures the clinical aspects. This condition leads to different perception of the real definition of the quality of life in patients with asthma. To improve the quality of treatment of asthma, not only it is necessary to determine the ability of the indicators to measure the quality of life in patients with asthma comprehensively, but also it must be valid, reliable, practical, and cost-effective.

\section{Methodology:-}

This research was preceded by development of the research instrument. This approach was based on many references and deep interviews. The interviews were conducted to some pulmonologists. The number of informants/respondents required was 10 . But this number was also determined by data saturation. The implication of the qualitative research was explorative, flexible, reflective, opened, and was developing continuously during the research ${ }^{5}$. The second step was the quantitative study approach by determining the validity and reliability of the instrument chosen in the first step.

The population was patients with asthma in Medan city. The inclusion criterias are: adult patients with asthma ranging 18-60 years old, patients looking for treatment from general practitioners or pulmonologists in Medan city, had been treated with standard asthma medicine (inhaled corticosteroid and long-acting $\beta_{2}$ agonists / LABA) at least 6 months, the patients were stable (not in asthma attack), the patients selected were those who had complete address data and were ready to be involved in this research (with informed consent). The exclusion criterias are: those with comorbid diseases, such as COPD (Chronic Obstructive Pulmonary Disease), heart diseases, diabetes mellitus, hypertension, renal and liver diseases, and those who were allergic to the medicines used in this research, patients with moderate or severe asthma who were hospitalized.

The sample was some of the patients looking for treatment from general practitioners or pulmonologists. The sampling method used in quantitative study was consecutive sampling, the sampling method based on the criterias chosen by the researchers. Consecutive sampling was the best method non-probability sampling. The number of sample was calculated by the single proportion hypothesis test formula ${ }^{6}$. The number of sample in this research was 200.

The primary data was used in this research. Data in the second step in this research was collected by interviews and structured questionnaires filled by the respondents directly. The basic of this method used is the self-reported conditions by the patients with asthma. This data of the quality of life was collected in one point. The quality of life 
was assessed by the quality of life reported by the patients individually. The interviews and filling of the questionnaires were done after getting consents from the patients in their house or where the patients were getting their treatment controlled. Interviews were conducted by the researcher in cooperation with medical students of Universitas Sumatera Utara or some nurses trained by the researcher. Some of the interviewers demonstrated how the questionnaires should be filled before the researcher. This was meant to obtain the valid data from the patients with asthma. The data was collected in 14 months. The data was analyzed by using Pearson correlation analysis to determine the validity, and Alpha Cronbach to determine the reliability. Besides, the researcher also used the confirmatory analysis to determine the validity and unidimentional of the analyzed instrument. This analysis determine the goodness of fit with some indexes, such as chi square, CMINDF, RMSEA, TLI, CFI, and AGFI. The Critical Ratio value $\mathrm{p}<0.05$ is used to determine the significant of the model and loading factor to determine the unidimentional of each indicators ${ }^{7,8,9}$.

Ethical clearance was obtained from the Commission of Ethics in Health Research in Medical School of USU. The respondents participated voluntarily, and have the rights to reject or withdraw themselves during the data collection.

\section{Results:-}

This research was generally divided into 2 steps. The first step was the qualitative approach and the second step was the quantitative approach. The qualitative approach aimed to develop the research instrument and the quantitative approach to analyze it. In this step, the researcher used the qualitative explorative approach. This was conducted in 6 months. The researcher selected 10 informants from medical people.

\section{Characteristic of Informant}

The selected informants must fulfilled the criterias as following:

1) General practitioners and pulmonologists who understood the problems and treatments of patients with asthma.

2) Had experiences at least 3 years as pulmonologists either at house or in the hospital

3) Being an informant in this research voluntarily

The informants selected was 7 pulmonologists and 3 general practitioners. Pulmonologists were doctors who were professional clinicians as well as lecturers in medical faculty. General practitioners were doctors who were lecturers in medical faculty. One of the 3 general practitioners was a patient with asthma and was using inhaler. The second one was a general practitioner specializing in public health and the other in pharmacology. The number was the same between the male and female, and the proportion of those in 41-50 years old was 70\%.

\section{Demographics of Patients with Asthma in Medan City:-}

The characteristics of patients with asthma were as the following:

Table 1:- Demographics of Patients with Asthma in Medan City

\begin{tabular}{|l|l|l|}
\hline Variable & $\mathrm{n}$ & $\%$ \\
\hline Age & & \\
\hline$\leq 20$ & 44 & 22 \\
\hline $21-30$ & 44 & 22 \\
\hline $31-40$ & 33 & 16.5 \\
\hline $41-50$ & 41 & 20.5 \\
\hline $51-60$ & 38 & 19 \\
\hline Gender & & \\
\hline Male & 74 & 37 \\
\hline Female & 126 & 63 \\
\hline Education & & \\
\hline Elementary School & 9 & 4.5 \\
\hline Junior High School & 11 & 5.5 \\
\hline Senior High School & 84 & 42 \\
\hline College & 96 & 48 \\
\hline Marital Status & & \\
\hline Married & 126 & 63 \\
\hline Unmarried & 74 & 37 \\
\hline Occupation & & \\
\hline
\end{tabular}




\begin{tabular}{|l|l|l|}
\hline Unemployment & 11 & 5.5 \\
\hline Housewife & 40 & 20 \\
\hline Stundents/college student & 40 & 20 \\
\hline Civil Servant/Army/Police & 35 & 17.5 \\
\hline Private Employee & 28 & 14 \\
\hline Enterpreneur & 31 & 15.5 \\
\hline Etc & 15 & 7,5 \\
\hline Income & & \\
\hline$<1$ million & 29 & 14.5 \\
\hline $1-3$ million & 93 & 46.5 \\
\hline $4-5$ million & 35 & 17.5 \\
\hline$>5$ million & 43 & 21.5 \\
\hline Ethnic & & \\
\hline Batak & 92 & 46 \\
\hline Java & 48 & 24 \\
\hline Malay & 11 & 5.5 \\
\hline Minang & 25 & 12.5 \\
\hline Aceh & 13 & 6.5 \\
\hline Etc & 11 & 5.5 \\
\hline
\end{tabular}

\section{Question Items for Quality of Life in Patients with Asthma:-}

The quality of life in patients with asthma was determined by 4 indicators, i.e. health, emotion, environment, and activity with the number of questions was 16 . The indicators was divided into 3 items about health, 4 about emotion, 5 about environment, and 4 about activity. The indicators were interpreted as $1=$ very often, $2=$ often, $3=$ sometimes, $4=$ seldom, and $5=$ never.

Details of questionnaire items is shown in Table 2.

Table 2:- Details of Questionnaire Items for the Quality of Life in Patients with Asthma..

\begin{tabular}{|l|l|}
\hline No & Variable \\
\hline & Health \\
\hline 1. & In the last 4 weeks, how often have you coughed? \\
\hline 2. & In the last 4 weeks, how often were you breathless? \\
\hline 3. & In the last 4 weeks, how often did asthma wake you up in the night/early morning? \\
\hline & Emotion \\
\hline 2. & In the last 4 weeks, how often were you worried about not getting medicine? \\
\hline 3. & In the last 4 weeks, how often were you worried and depressed about your disease? \\
\hline 4. & In the last 4 weeks, did you feel uncomfortable/unhappy? \\
\hline & In the last 4 weeks, how often did asthma disturb your interaction with other? \\
\hline 1. & Environment \\
\hline 2. & In the last 4 weeks, how often were you disturbed by dust? \\
\hline 3. & In the last 4 weeks, how often were you disturbed by cigarette smoke? \\
\hline 4. & In the last 4 weeks, how often were you disturbed by air pollution? \\
\hline 5. & In the last 4 weeks, how often were you disturbed by the weather (cold/warm)? \\
\hline & Activity \\
\hline 1. & In the last 4 weeks, how often did asthma disturb your work (office, household, school activity, etc)? \\
\hline 2. & In the last 4 weeks, how often did asthma disturb your daily activities (eating, bathing, climbing stairs, etc)? \\
\hline 3. & In the last 4 weeks, how often did asthma disturb your sport or heavy physical activities? \\
\hline 4. & $\begin{array}{l}\text { In the last } 4 \text { weeks, how often did asthma disturb your social activities (organizing, visiting friends, social } \\
\text { gathering, etc)? }\end{array}$ \\
\hline
\end{tabular}

The Results of Validty and Reliability Testing of the Instruments of Quality of Life:-

The results of validity and reliability testing of all the indicators for the quality of life in patients with asthma is shown in the table below. All the indicators showed the Alpha Cronbach value $>0.8$. 
Table 3:- The Results of Validty and Reliability Testing of the Instruments of Quality of Life in Patients with Asthma

\begin{tabular}{|l|l|l|l|}
\hline Variable & Dimension & Question Items & Alpha Cronbach \\
\hline Quallity of Life & Health & 3 & 0.834 \\
\hline & Emotion & 4 & 0.826 \\
\hline & Environment & 5 & 0.801 \\
\hline & Activity & 4 & 0.836 \\
\hline Total Quality of Life & & 16 & 0.929 \\
\hline
\end{tabular}

Analysis of Construct Confirmatory Factor of Quality of Life in Patients with Asthma:-

The following table describes the goodness of fit model of all the indicators determined as the instrument to measure the quality of life in patients with asthma. The goodness of fit test result was in the good category.

Table 4:- Goodness of Fit Test for Quality Variable.

\begin{tabular}{|l|l|l|l|}
\hline Indicators & & & \\
\hline Chi Square & Smaller & 0.509 & Good \\
\hline Probability & $\geq 0.05$ & 0.775 & Good \\
\hline CMIN/DF & $\leq 1.96$ & 0.266 & Good \\
\hline GFI & $\geq 0.90$ & 0.999 & Good \\
\hline AGFI & $\geq 0.90$ & 0.994 & Good \\
\hline TLI & $\geq 0.95$ & 1.014 & Good \\
\hline CFI & $\geq 0.95$ & 1 & Good \\
\hline RMSEA & $\leq 0.08$ & 0.0001 & Good \\
\hline
\end{tabular}

The results of significant test of weight factor is shown in the table below. The result shows high value of CR (identical to t-test) and probability value $<0.05$. This result indicates that these variables play a significant role as the dimension of latent factor for the quality of life. The loading factor value for all indicators was $>0.5$.

Table 5:- The Results of Significant Test of Weight Factor for Variables of Quality of Life.

\begin{tabular}{|l|l|l|l|l|l|}
\hline Correlation & Estimate & SE & CR & P & Load \\
\hline Health $\leftarrow$ quality of life & 1.00 & & & & 0.71 \\
\hline Emotional $\leftarrow$ quality of life & 1.40 & 0.14 & 10.05 & 0.0001 & 0.78 \\
\hline Environment $\leftarrow$ quality of life & 1.46 & 0.18 & 8.25 & 0.0001 & 0.64 \\
\hline Activity $\leftarrow$ quality of life & 1.71 & 0.16 & 10.59 & 0.0001 & 0.87 \\
\hline
\end{tabular}

\section{Discussion:-}

The instrument for quality of life in patients with asthma in this research was developed based on 4 indicators, mentioned as health, emotion, environment, and activity. The total items in the questionnaire was 16 that consisted of 3 items for health, 4 for emotion, 5 for environment, and 4 for activity.

Study on development of quality of life questionnaire for patients with chronic diseases has been widely conducted. To assess the quality of life in chronic diseases, SF36, which consists of 8 sub-scales such as physical function, physical limitations, pain sensation, general health perception, energy/fatigue, social function, emotional limitation, and mental prosperity, can be used. SF36 consists of 36 questions $^{2,10}$.

SF36 can be used to measure the quality of life in patients with chronic diseases, including asthma. But, the study of quality of life in patients with asthma has been widely conducted. AQLQ was developed by Junifer et al in 2005. This questionnaire aimed to measure the quality of life in patients with asthma > 17 years old (adults). The questionnaire consists of 32 questions, in which the measured dimensions are symptoms, emotional, environment, and limitation of activity. Alpha Cronbach value of this questionnaire is $0.93^{3}$. In Australia, a questionnaire to measure the quality of life, namely AQLQ-Sydney, has been developed. This questionnaire consists of 20 questions, which make it more simple than AQLQ developed by Junifer et al. The value of Alpha Cronbach obtained is $0.97^{11}$. In this research, the researcher managed to develop a questionnaire for the quality of life that is more simple than some research previously. It consists of 4 dimension of quality of life (health, emotion, environment, activity) with the total number of 16 questions.

The value of Alpha Cronbach is 0.929, obtained from the results of validity test. The questionnaire obtained in this research was named by the researcher as AQLQ-Medan which can be used by general practitioners or 
pulmonologists to assess the quality of life in patients with asthma in Medan city, especially adults who are receiving standard asthma treatment. Azwar mentioned that the criteria for a good instrument is not only valid and reliable, but also practical and cost-effective ${ }^{12}$.

The result of evaluation of quality of life variable model shows significant level $>0.05$. This means that there is no difference between estimated covariant matrix of the sample and population in which the model is accepted/suitable. Moreover, the goodness of fit indexes such as Chi square, probability, CMIND/DF, GFI, AGFI, TLI, CFI, RMSEA are in good category. This indicates that the quality of life measurement model is a good model to describes the quality of life aspect in patients of asthma in Medan city.

The results of research also shows the values of loading factor for 4 indicators, such as health, emotion, environment, an activity are $0.72,0.78,0.64$, and 0.87 , respectively. It can be concluded that these 4 indicators of variables significantly represent the unidimensional for latent quality of life variable.

The capability of those dimensions to form the latent factor can be analyzed by using the t-test to regression weight ${ }^{7,8,9}$. The result of research shows high value of $\mathrm{CR}$ (identical to t-test) and probability value $<0.05$. The result of this test indicates that the variables significantly represent the dimensions for latent quality of life factor.

Indicators for latent quality of life variable has shown unidimentionality. Furthermore, it determines that the indicators of quality of life are in the same dimension and can be used to measure the quality of life in patients with asthma, especially in Medan.

\section{Conclusions and Suggestions:-}

The conclusion of this research is that the measurement model for the quality of life in patients with asthma in Medan city has a good psychometric value, as it is valid, reliable, fit modeling, practical, and cost-effective.

AQLQ-Medan can be used by clinicians to assess the quality of life in patients practically, cost-effectively, and reliably.

\section{Bibliography:-}

1. Hyland ME. Assessment of quality of life in chronic lung disease. In: Morgan M. Sally S Eds. Practical pulmonary rehabilitation. Chapman and Hal Medical, London.2004. p. $47-63$.

2. Imelda, S., Yunus F., Wiyono, W.H. Relationship Asthma Level with Life Quality with Measure of Asthma Quality of Life Questionnaire. 2007. MKI 57 (12): 435-335.

3. Junifer EF, Svenson K, Mork AC, Stahl E. Modification of the Asthma Quality of Life Questionnaire (Standardised) for patients 12 years and older. 2005. Biomed Central: $1-6$.

4. Scahtz M, Soerkness C, James T, Marcus P, Murray J, Nathan R. Asthma Control Test: Reliability, validity, and responsiveness in patients not previously followed by asthma specialists. 2006. J. Allergy. Clin. Immunol 117 (3): 449-556.

5. Patilima H. Qualitative Research Method. CV Alfabeta, Bandung. 2005. 1-15.

6. Lemeshow S, Hosmer D, Klar J, Lwanga S. Measure Sample in the Medical Reseach. Gadjah Mada University Press, Jogyakarta 1997. 1-11.

7. Hair JF, Anderson RE, Tatham RL, Black WC. Multivariate data analysis. Sixth Edition. Pearson-Prentice Hall USA 2006.

8. Wibowo. Factor Analysis in Statistic Multivariate. 2008

9. Ferdinand A. Structural Equation Modelling in Management Research. Universitas Diponegoro, Semarang. 2002. p.1-241.

10. Lina. 2008. The relationship between parameters of nutritional status as measured by Bioelectric Impedance Analysis and quality of life were assessed with the SF 36 on regular hemodialysis patients, Department of Medical School of USU Adam Malik Hospital /Dr. Pirngadi Medan Hospital.

11. Miedingera D, Chajeda PN, Stolza D, Leimenstolla B, Tamma M, Fiechtera R. 2006. Reliability and validity of a German asthma quality of life questionnaire. Swiss.med 1 (36): 89-95.

12. Azwar S. 2001. Reliablity and Validity. 3th edition Pustaka Pelajar. Yogyakarta, Pustaka Pelajar: p.1-146. 